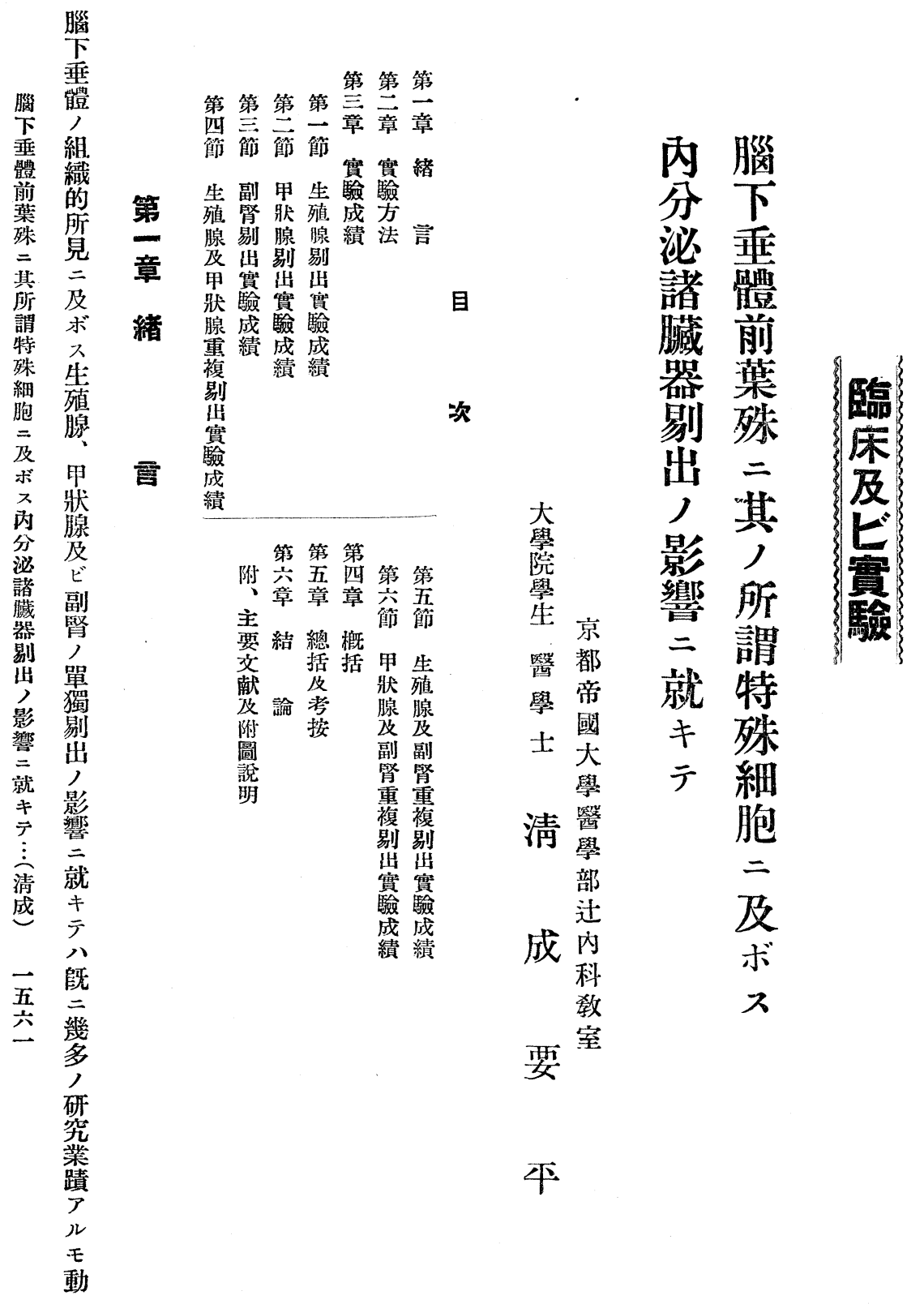




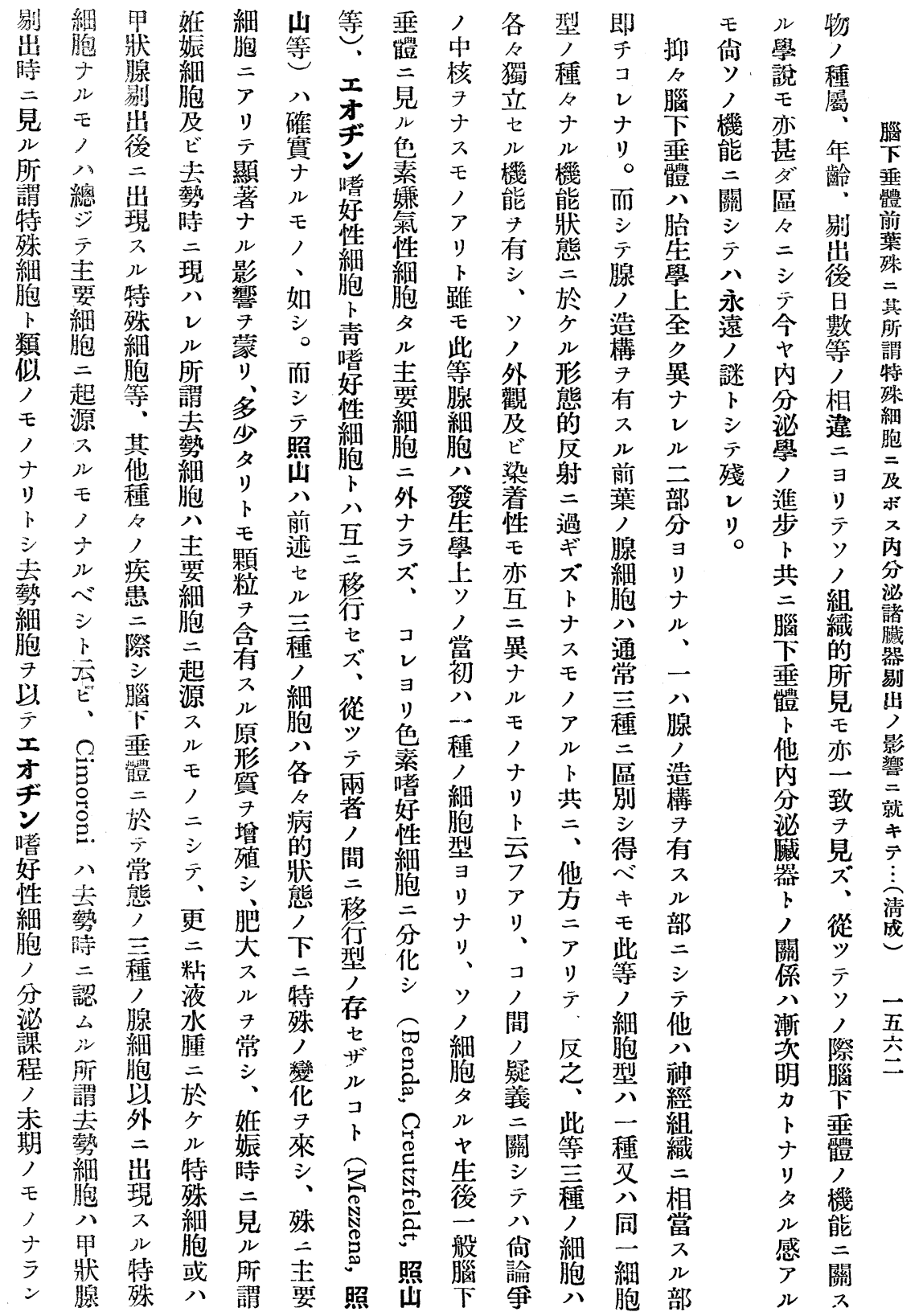




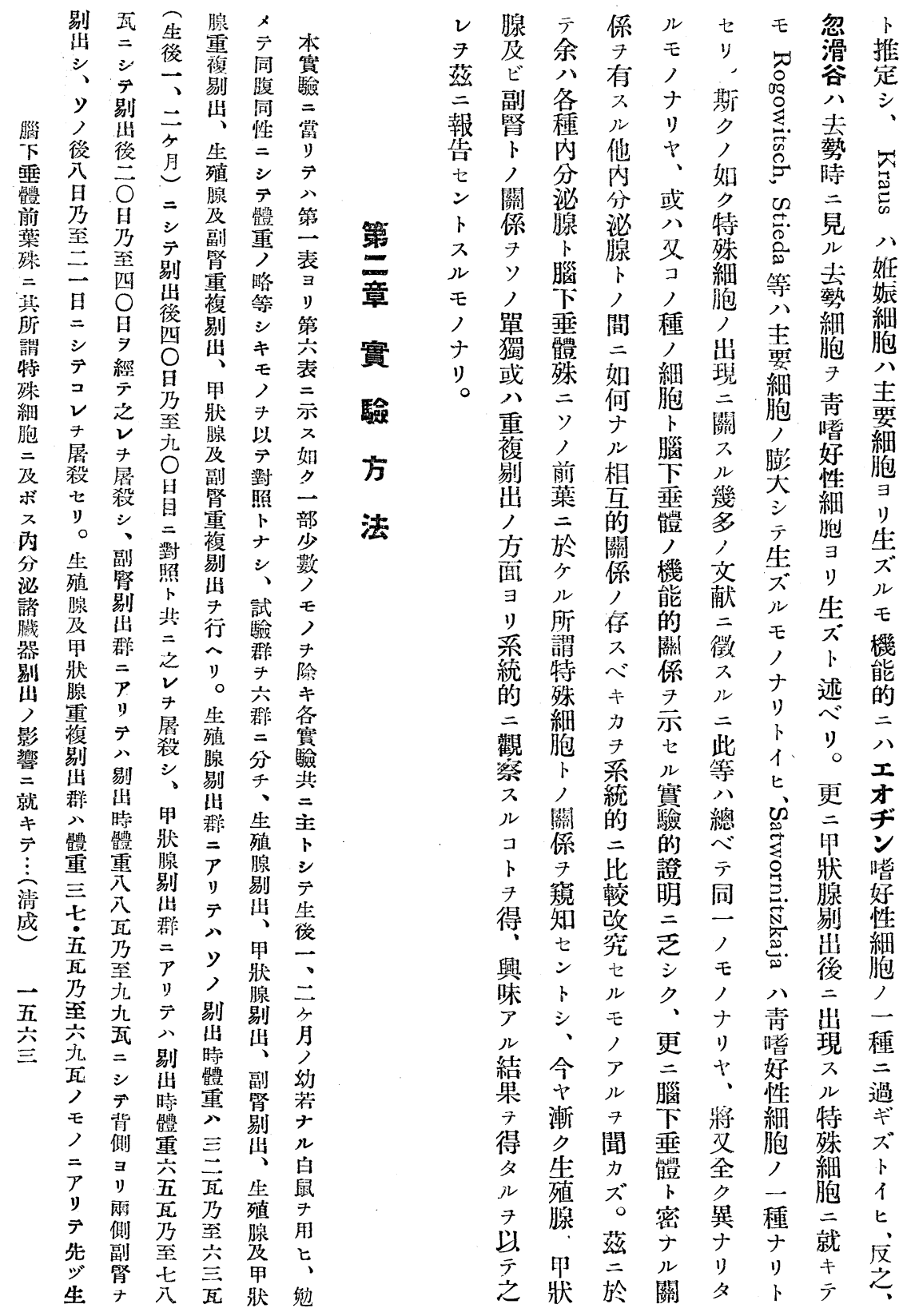




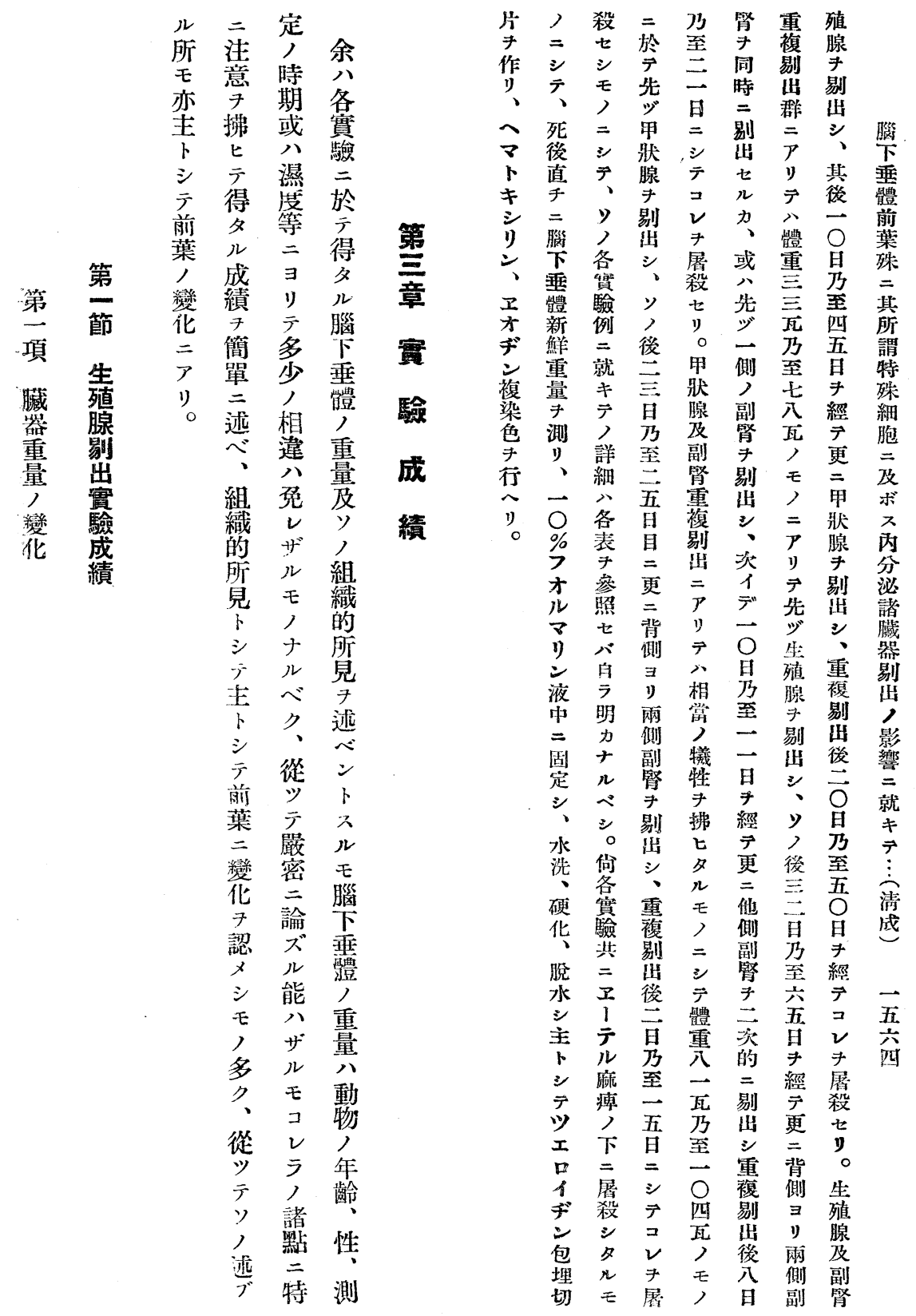




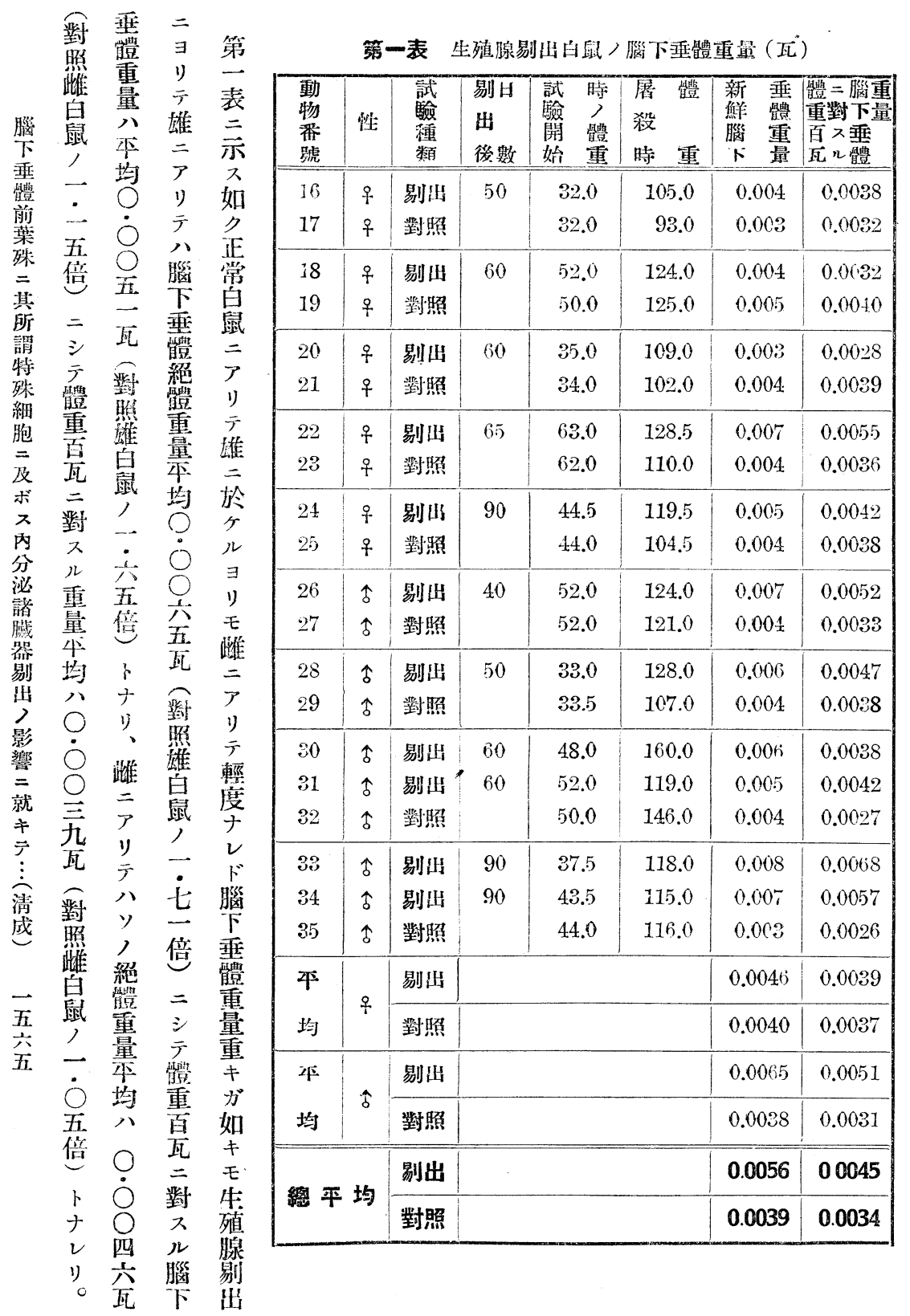




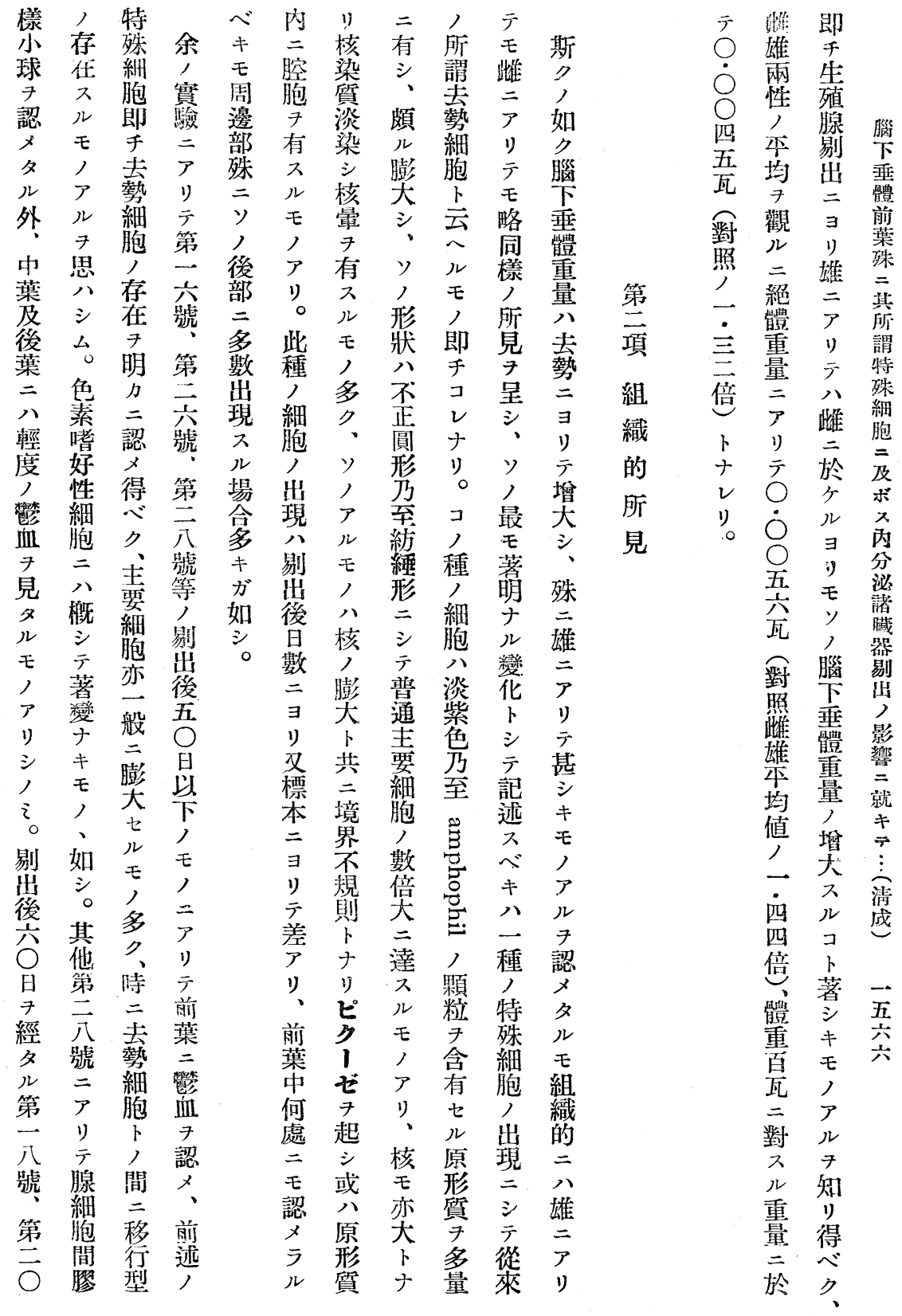




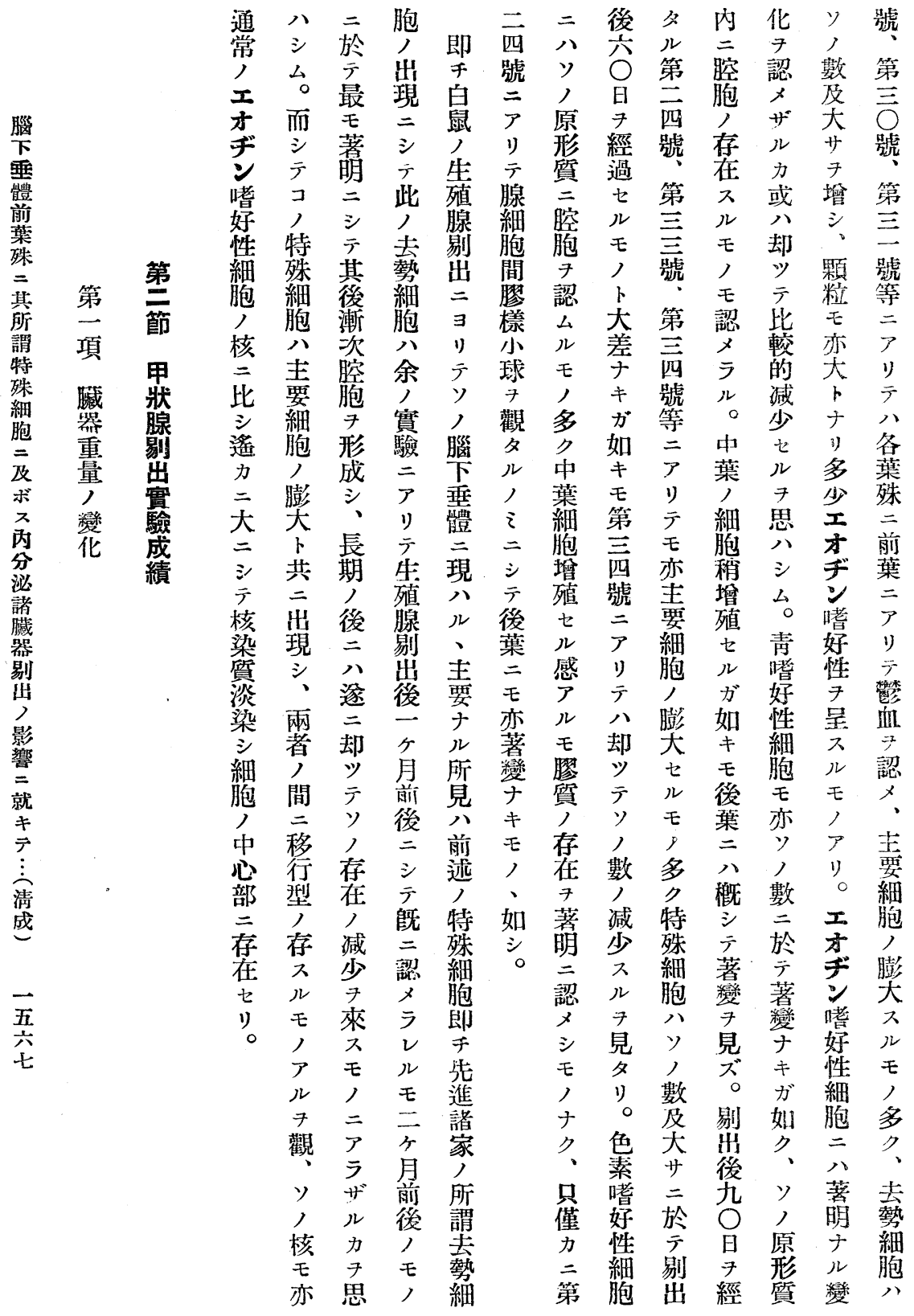




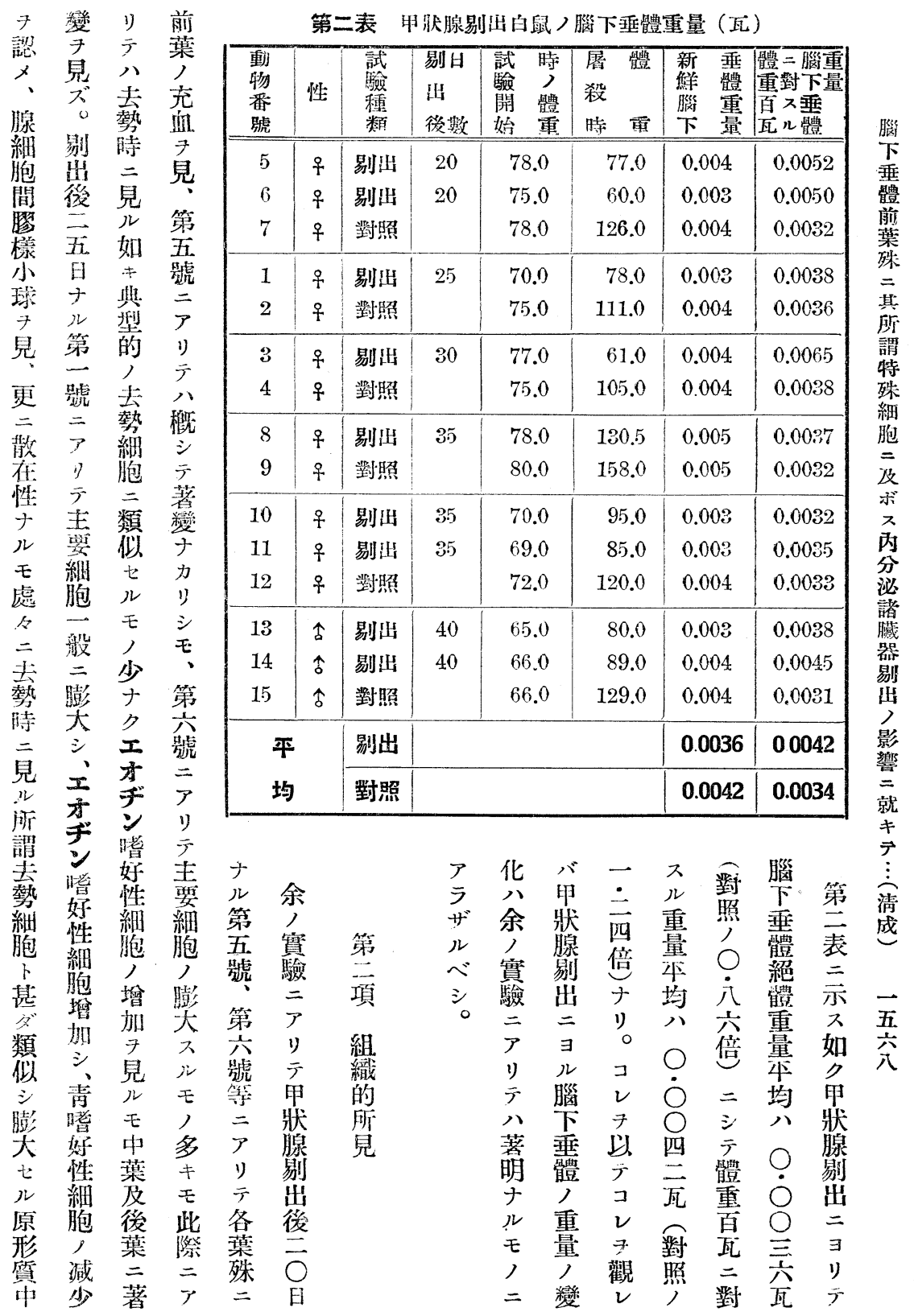




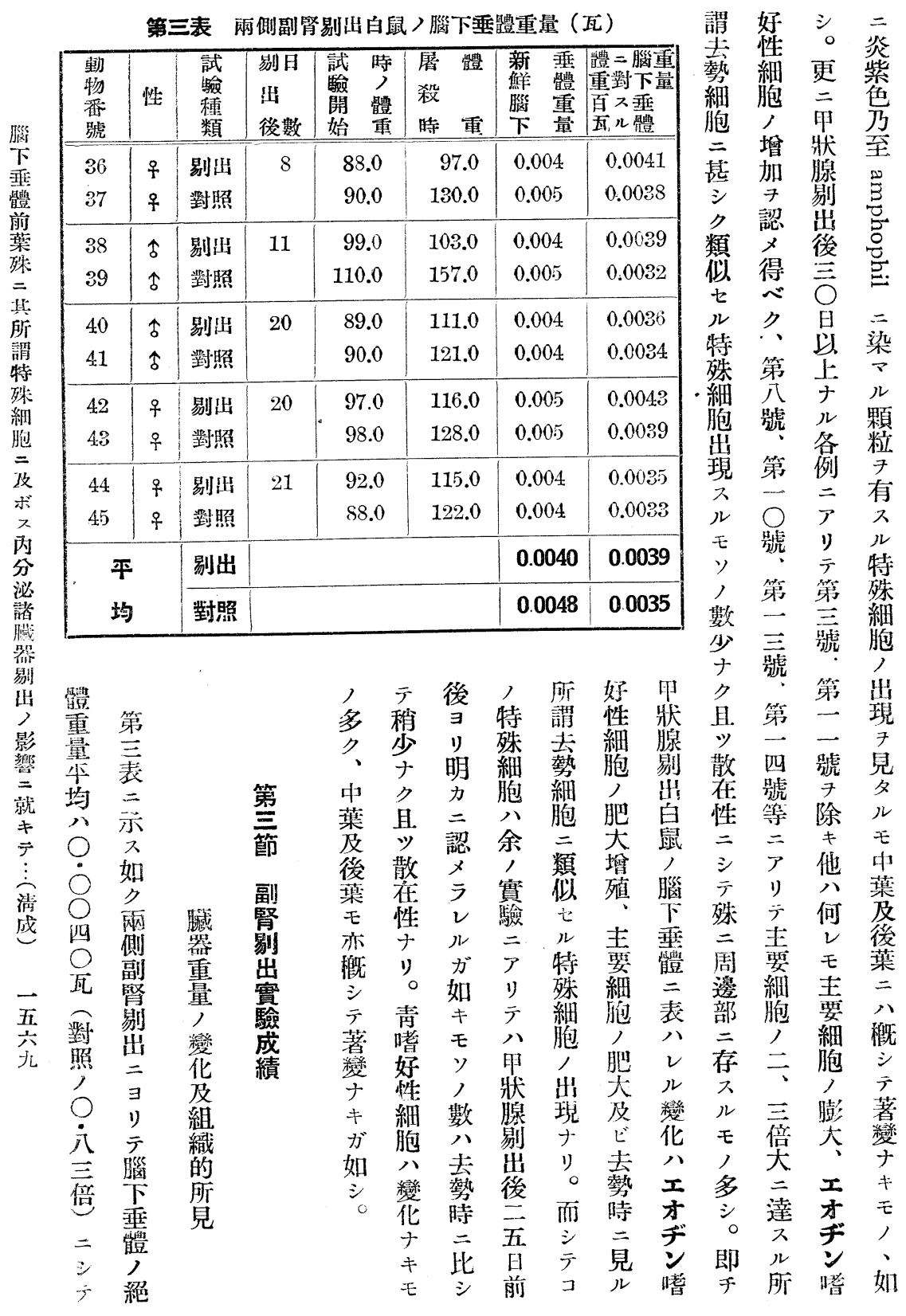




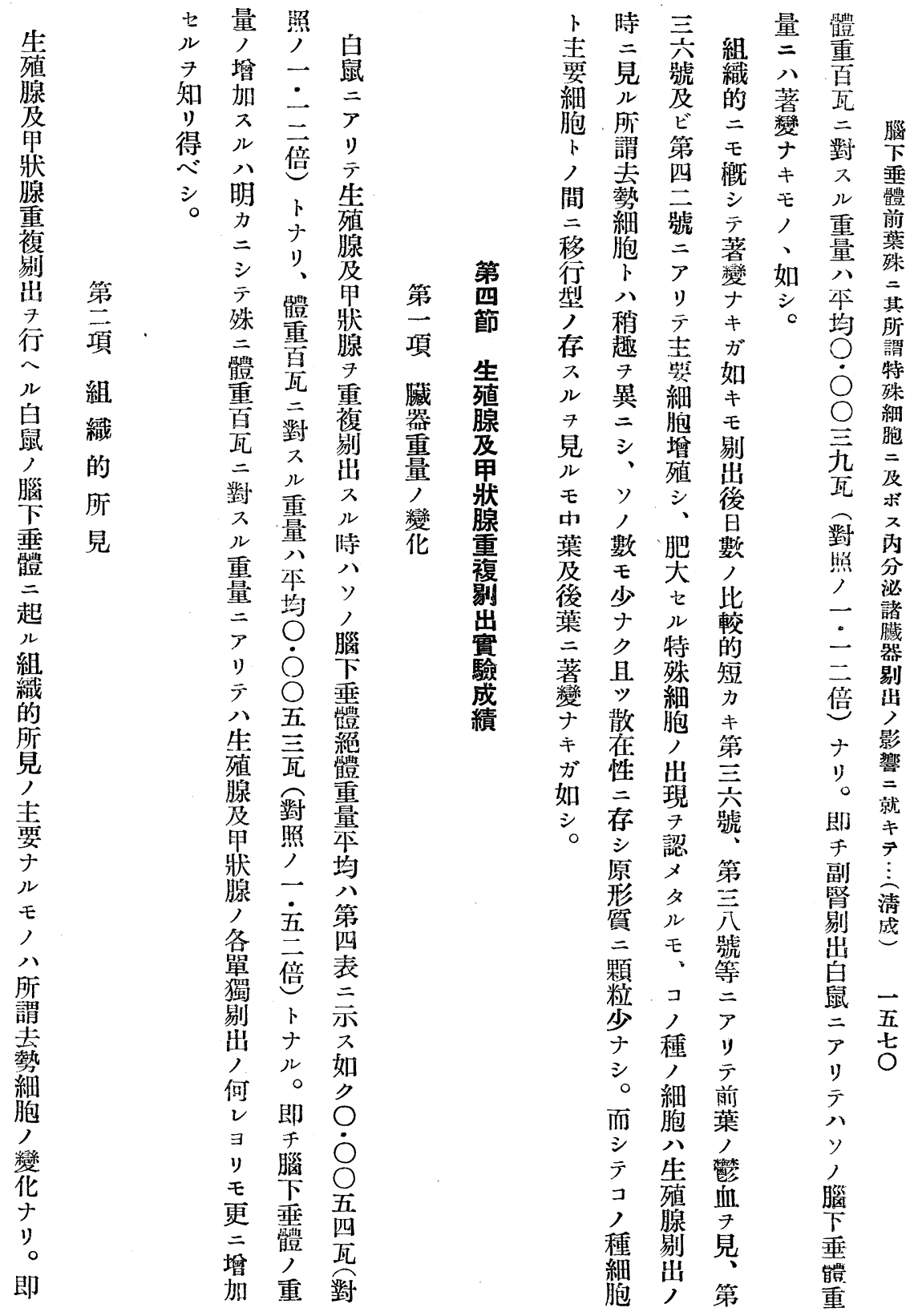




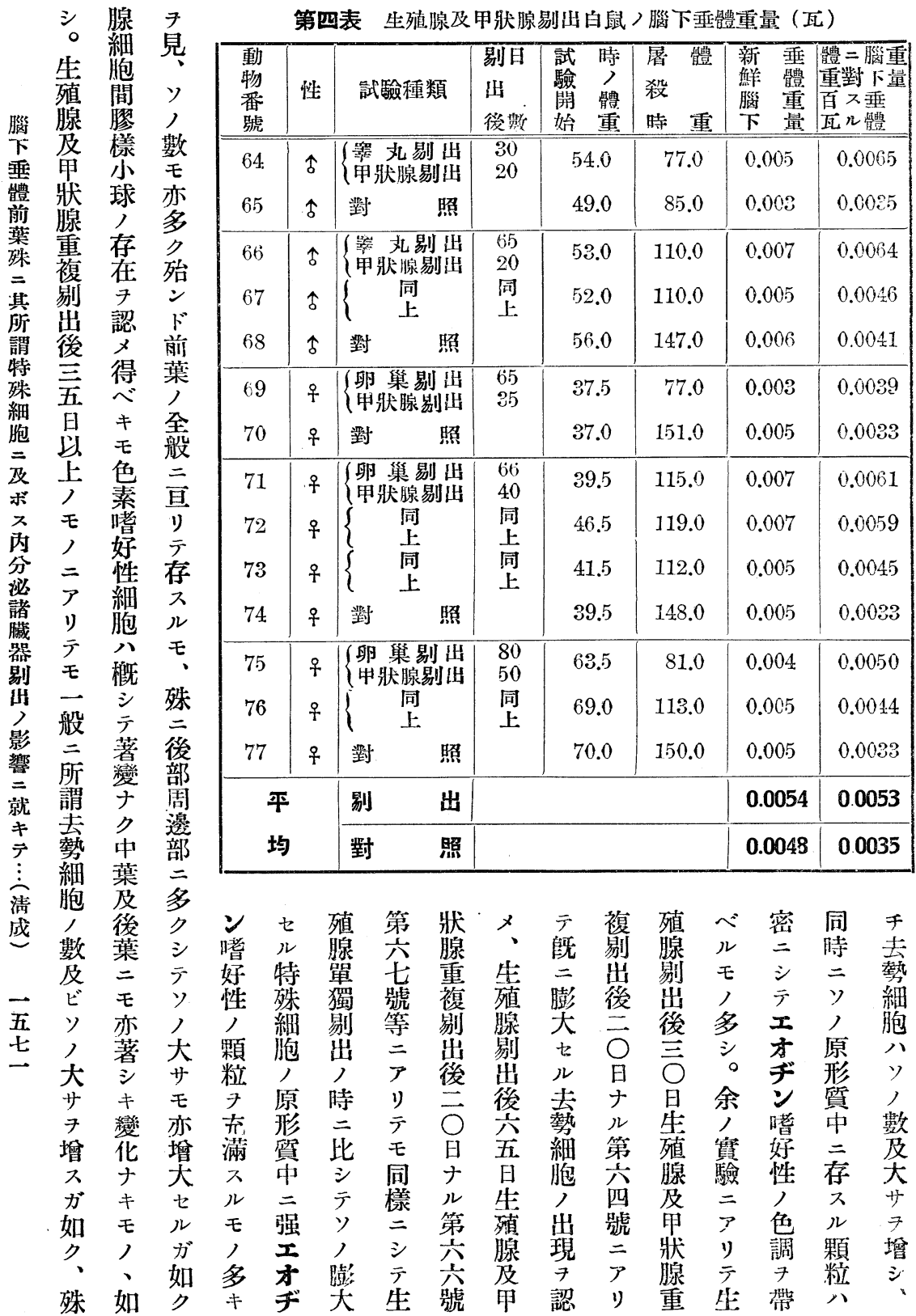




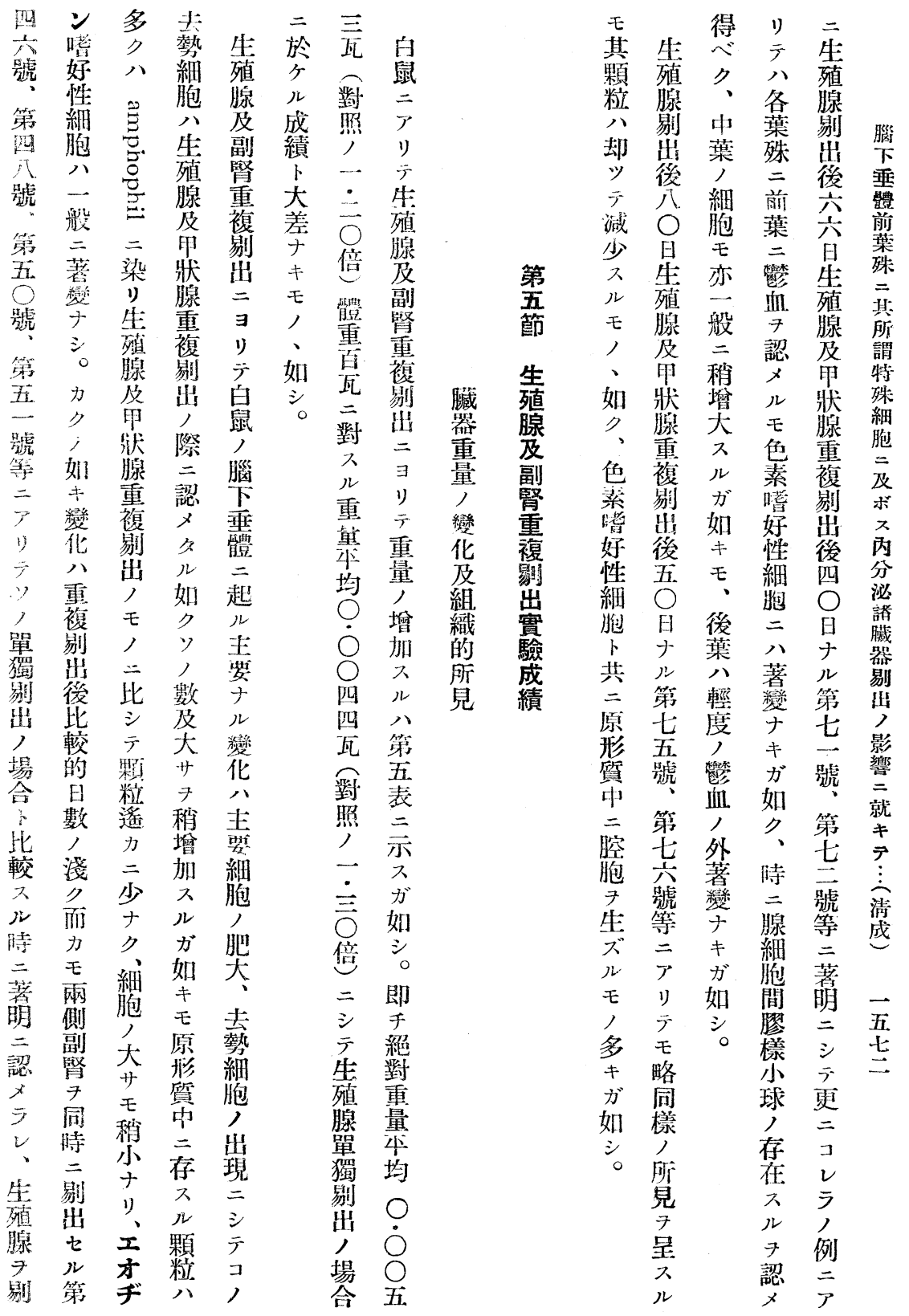


第五表 生殖腺及副督剔出白鼠>腦下垂體重量（瓦）

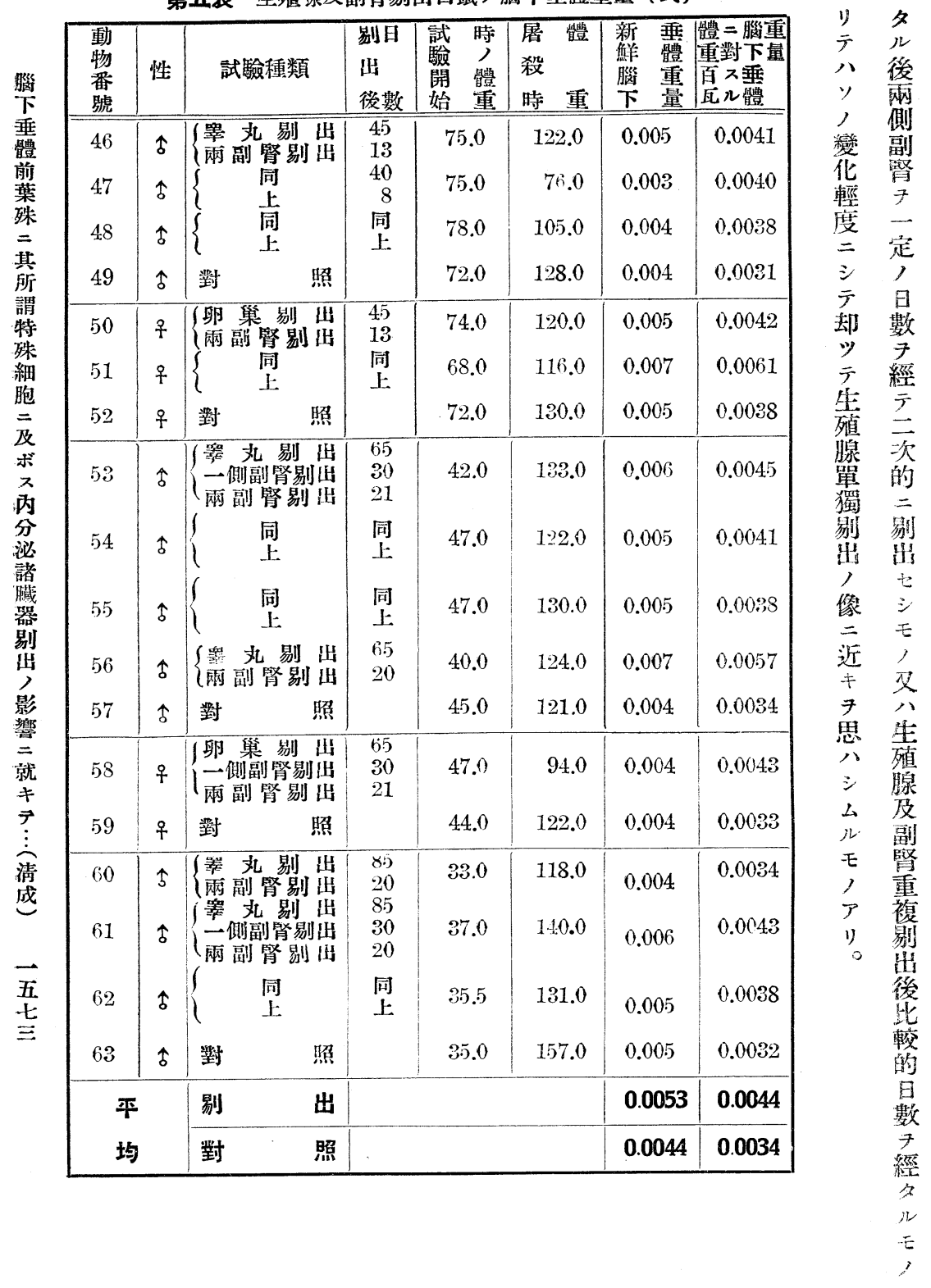




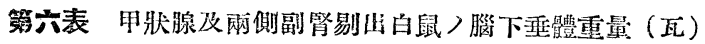

\begin{tabular}{|c|c|c|c|c|c|c|c|}
\hline $\begin{array}{l}\text { 㗥 } \\
\text { 物 } \\
\text { 悉 } \\
\text { 號 }\end{array}$ & 性 & 試驗種類 & $\begin{array}{l}\text { 剔日 } \\
\text { 结 } \\
\text { 後數 }\end{array}$ & $\begin{array}{l}\text { 試 } \\
\text { 驗 } \\
\text { 閔 } \\
\text { 體 } \\
\text { 始 重 } \\
\end{array}$ & 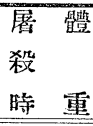 & $\begin{array}{ll}\text { 新 } & \text { 垂 } \\
\text { 鮮 } & \text { 體 } \\
\text { 䁩 重 } \\
\text { 下 量: }\end{array}$ & 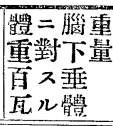 \\
\hline 78 & 令 & $\left\{\begin{array}{l}\text { 甲獎腺剔识 } \\
\text { 副腎剔出 }\end{array}\right.$ & $\begin{array}{r}25 \\
2\end{array}$ & 104.0 & 115.0 & 0.005 & 0.0044 \\
\hline 79 & $\hat{\delta}$ & $\left\{\begin{array}{l}\text { 同 } \\
\text { 上 }\end{array}\right.$ & $\begin{array}{r}30 \\
5\end{array}$ & 86.0 & 82.0 & 0.006 & 0.0075 \\
\hline 80 & 令. & 對照 & & 78.5 & 141.0 & 0.005 & 0.0025 \\
\hline 81 & q & $\left\{\begin{array}{l}\text { 甲狀湿剔山 } \\
\text { 副腎剔出 }\end{array}\right.$ & $\begin{array}{r}25 \\
2\end{array}$ & 83.0 & 74.0 & 0.004 & 0.00 .55 \\
\hline 82 & 우 & $\left\{\begin{array}{l}\text { 同 } \\
\text { 上 }\end{array}\right.$ & $\begin{array}{r}30 \\
7\end{array}$ & 81.0 & 75.0 & 0.006 & 0.0080 \\
\hline 83 & 우 & 對照 & & 77.0 & 118.0 & 0.004 & 0.0024 \\
\hline 84 & $\hat{\delta}$ & $\left\{\begin{array}{l}\text { 出狀腺剔出 } \\
\text { 副腎剔绢 }\end{array}\right.$ & $\begin{array}{l}40 \\
15\end{array}$ & 90.0 & 102.0 & 0.004 & 0.0039 \\
\hline 85 & 令 & $\left\{\begin{array}{l}\text { 同 } \\
\text { 上 }\end{array}\right.$ & $\begin{array}{l}40 \\
15\end{array}$ & 100.5 & 120.0 & 0.005 & 0.0042 \\
\hline 86 & 今 & 對 照 & & 88.0 & 153.0 & 0.005 & 0.0032 \\
\hline \multicolumn{2}{|c|}{ 平 } & 出 & & & & 0.0050 & 0.0056 \\
\hline \multicolumn{2}{|c|}{ 均 } & 㟄 & & & & 0.0047 & 0.0034 \\
\hline
\end{tabular}

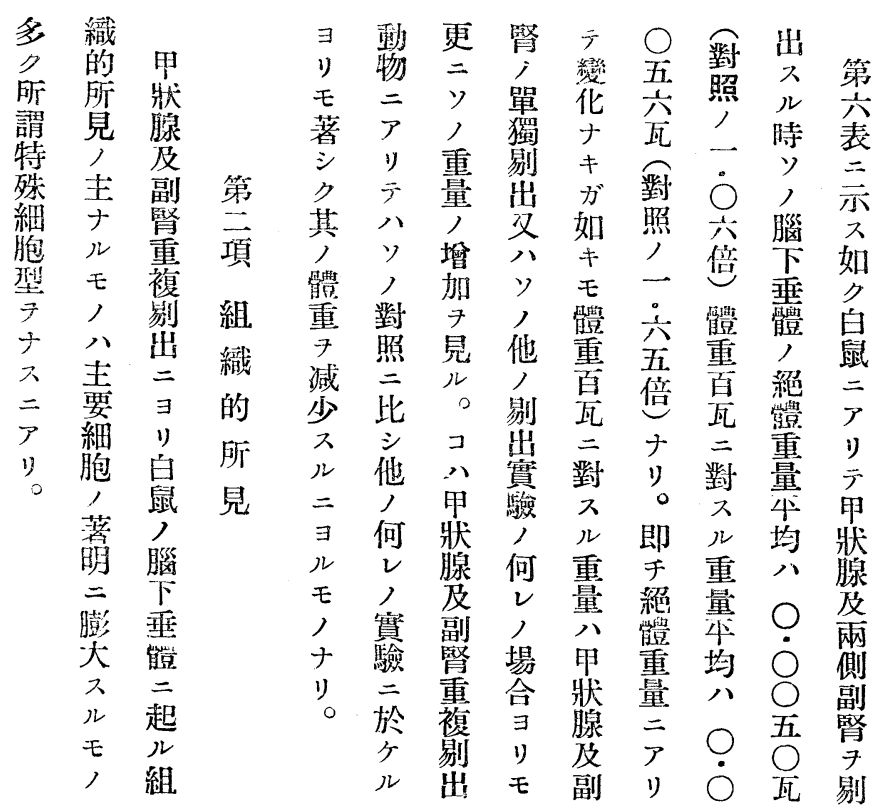



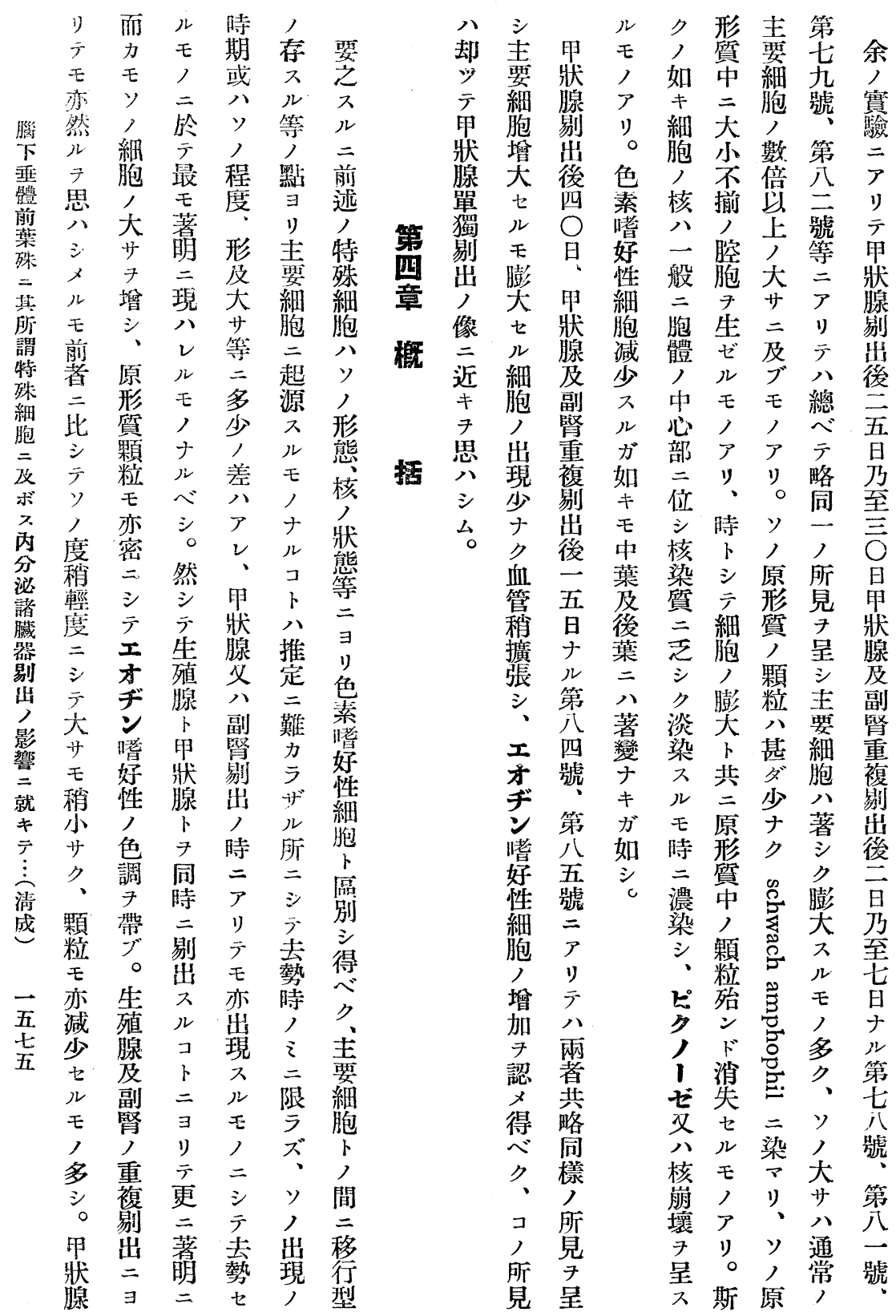

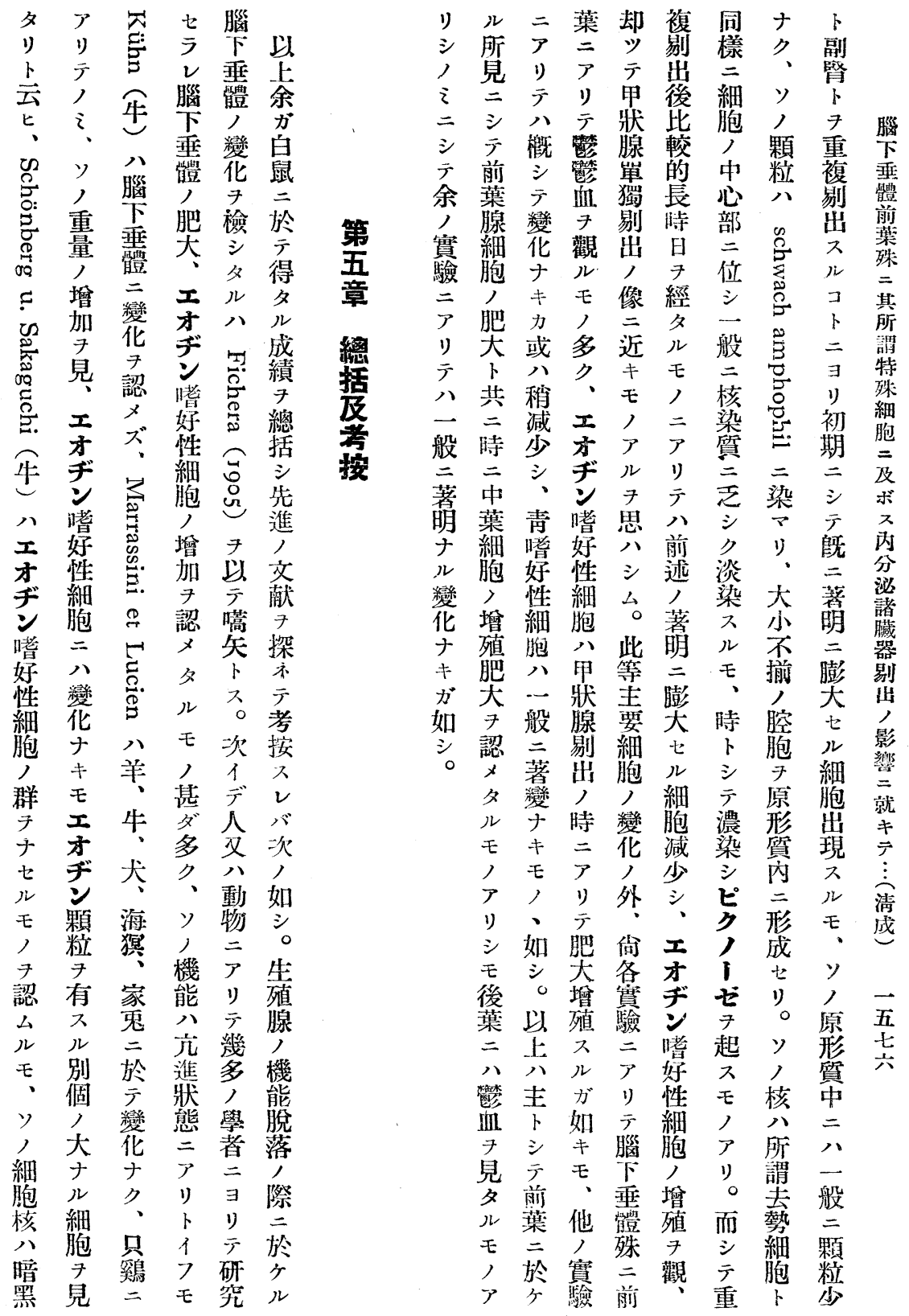


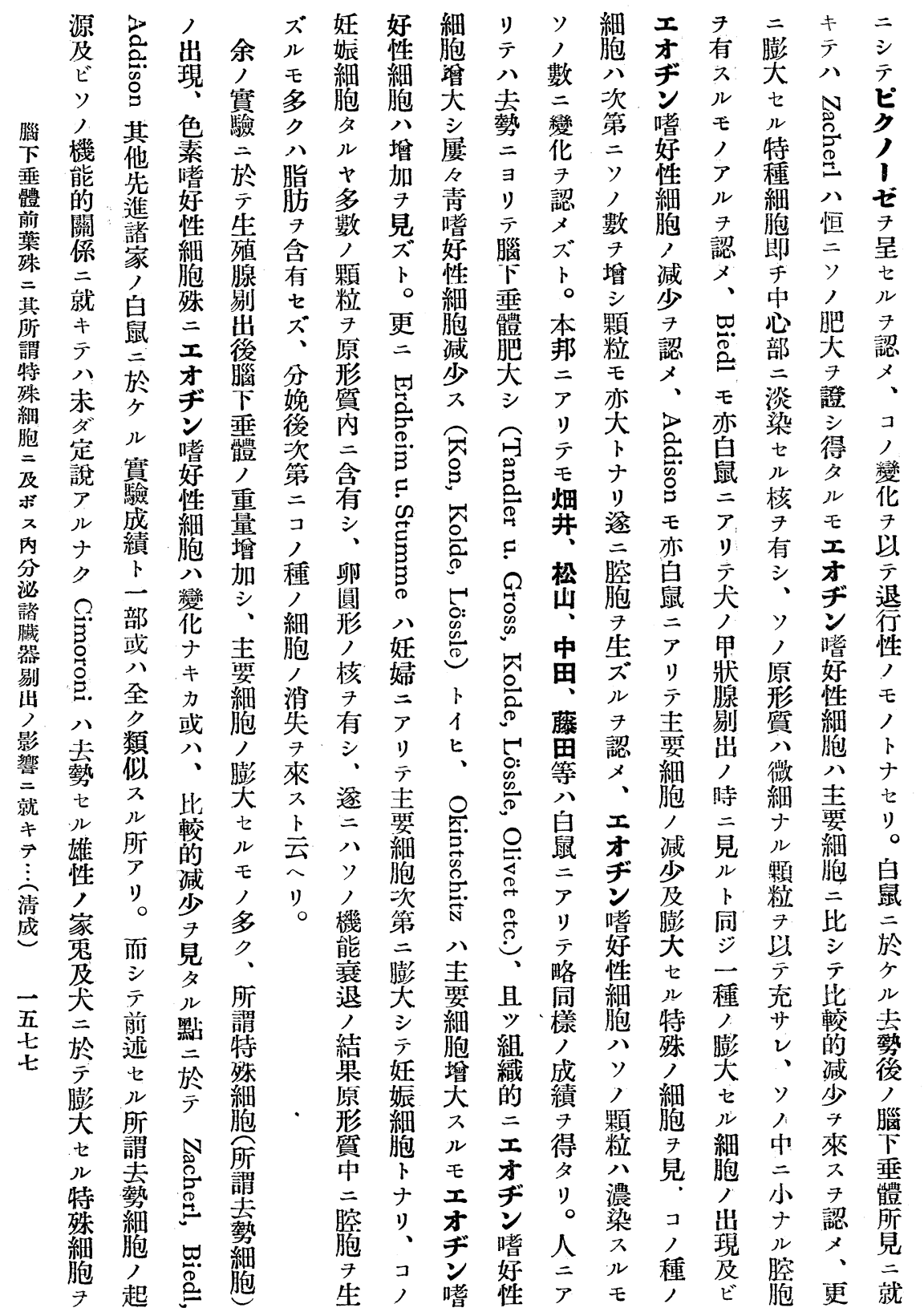




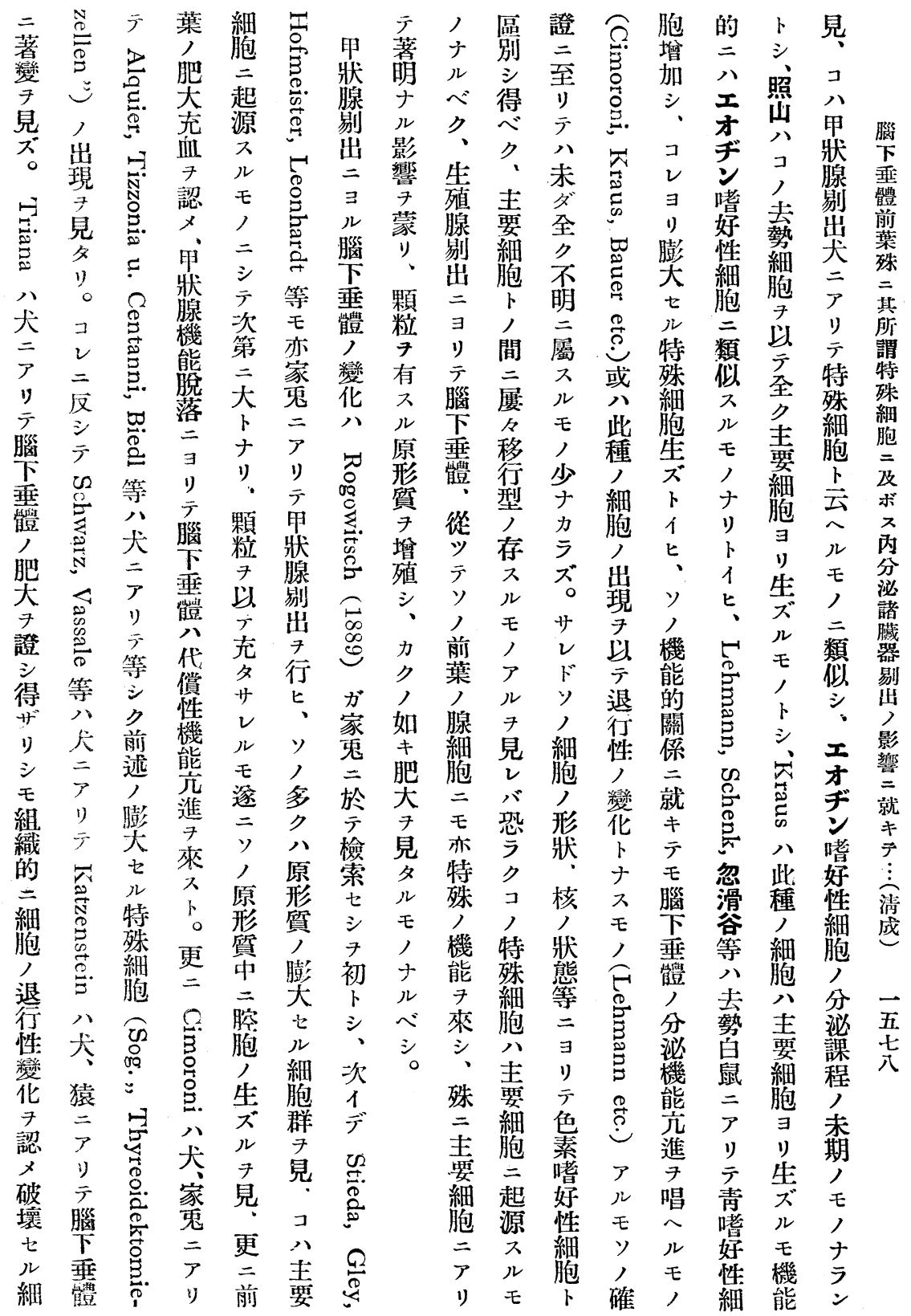




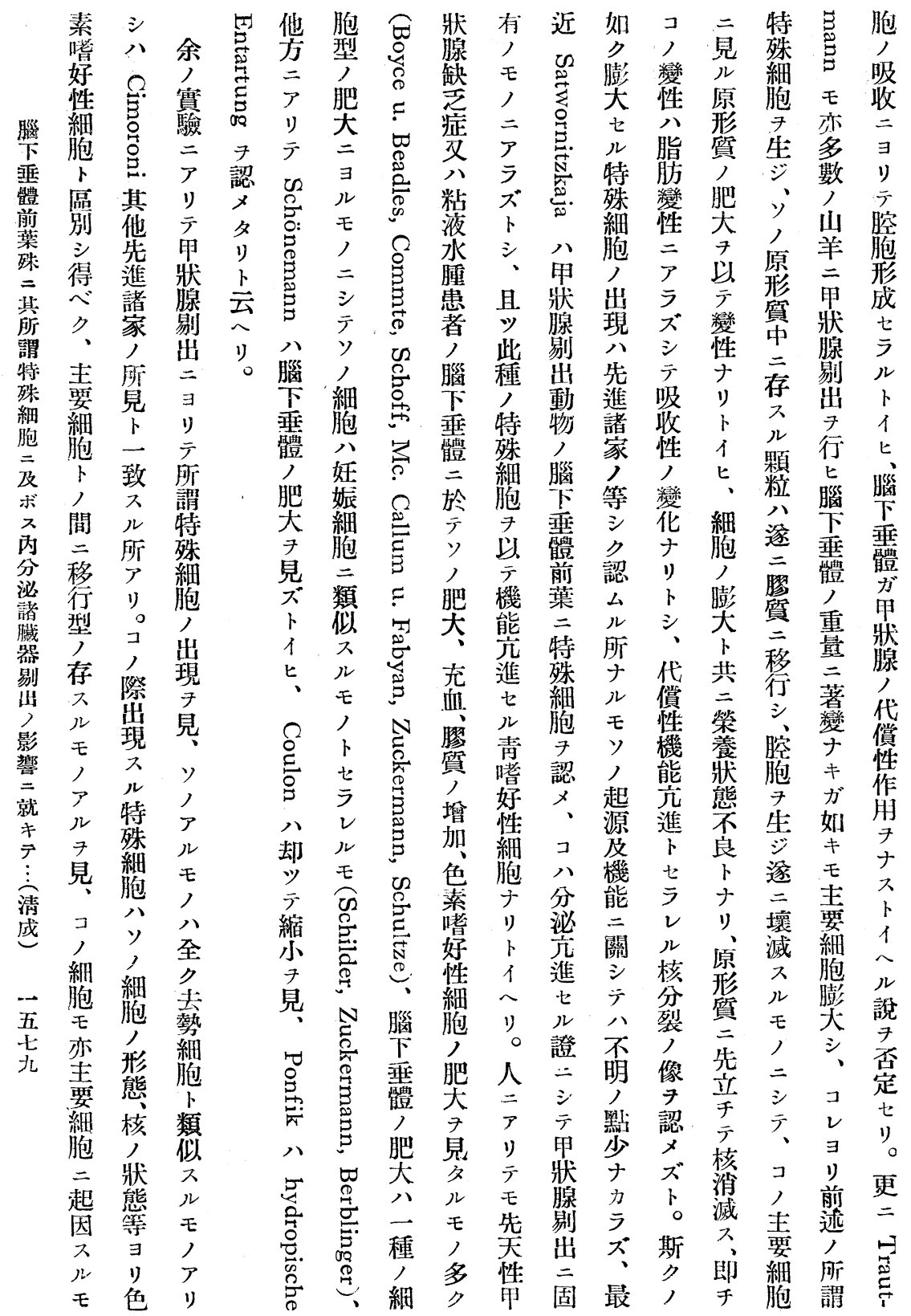




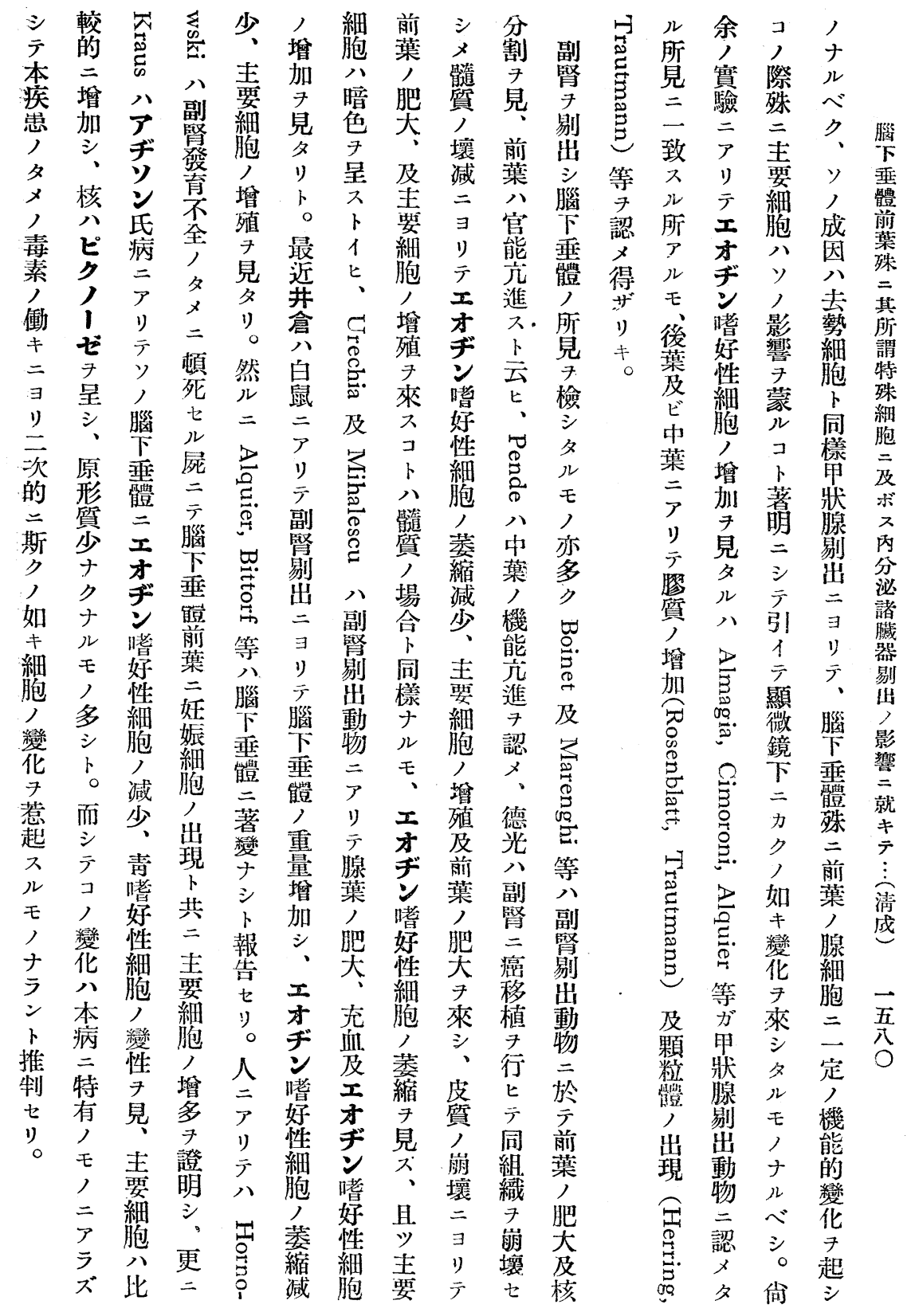




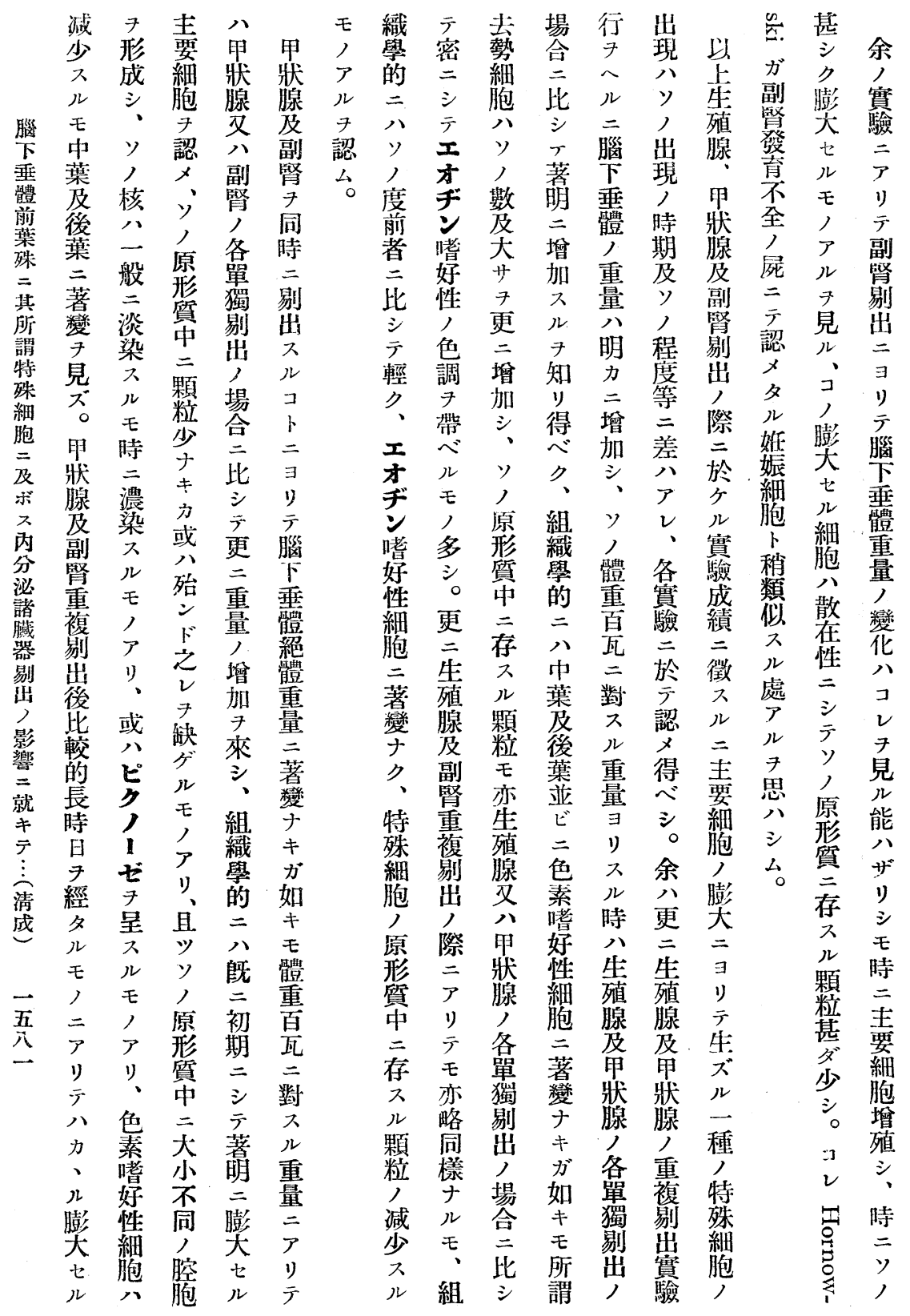




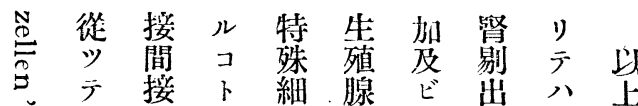

\begin{tabular}{|c|c|c|c|c|c|c|c|c|c|c|c|c|c|}
\hline$\stackrel{\varrho}{\varrho}$ & 從 & 授 & ル & 特 & 生 & 加 & 督 & リ & & & $=$ & & \\
\hline$\overline{\bar{B}}$ & & 間 & ב & 殊 & 殖 & 及 & 剔 & $\bar{r}$ & 以 & & $\boldsymbol{\gamma}$ & 胞 & \\
\hline$\because$ & 5 & 挼 & r & 細 & 腺 & ビ & 出 & 八 & 上 & & !) & 1 & \\
\hline ト & 奎 & $\overline{\overline{1}}$ & 推 & 胞 & 及 & Y & 俩 & 生 & 述 & & テ & 出 & \\
\hline 1 & 㭙 & $\frac{10 x}{T}$ & 㘹整 & 出 & 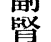 & 前 & $\begin{array}{l}\text { 际 } \\
=\end{array}$ & 腺 & 久 & & 副 & 堌 & 豚 \\
\hline$t$ & $=$ & 垂 & ス & 現 & 重 & 葉 & 於 & 䘞 & $\mu$ & & 安' & 岁 & 萛 \\
\hline 何 & 見 & 體 & U & $t^{\prime \prime}$ & 複 & $=$ & テ & 出 & 實 & & 粲 & 少 & 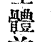 \\
\hline & 2 & (J48 & $\overline{\mathrm{z}}$ & 腦 & 剔 & 於 & ソ & $=$ & 謌 & 笣 & & ナ & \\
\hline $\begin{array}{l}t \\
\pm\end{array}$ & 所 & 機 & 難 & 下 & 出 & 5 & ) & $\exists$ & 成 & & 代 & ク & 篫 \\
\hline 勢 & 壁 & $\begin{array}{l}\text { 䏍 } \\
\mp\end{array}$ & カ & 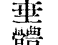 & 甲 & 斿 & 出 & $\stackrel{y}{=}$ & 䣔 & 枩 & 償 & ' & 改 \\
\hline 時 & 勢 & 亦 & ズ & 留 & 狀 & 謂 & , & 腦 & $\begin{array}{l}-3 \\
\mathrm{y}\end{array}$ & & 宱 & エ & 甚 \\
\hline 又 & 細 & y & o & 能 & 腺 & 特 & 度 & 㠿 & 結 & 結 & 用 & ヂ & 謂 \\
\hline 分 & 胞 & 1 & 即 & P & 及 & 殊 & 最 & 垂 & 論 & & $=$ & 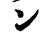 & 特 \\
\hline 狀 & 20 & 影能 & 千 & 如 & 副 & 細 & 正 & 體 & t & & $\exists$ & 喏 & 殊 \\
\hline 腺 & oga & 䜾 & $\vec{\pi}$ & 何 & 箠 & 妿 & 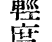 & 煟 & $\underline{-}$ & & ル & 恏 & 腊 \\
\hline 匏 & 7 & 蒙 & 公 & u & 袿复 & 現 & ナ & $=$ & 牛 & & $\vec{k}$ & 位 & $=$ \\
\hline 出 & $\hat{\approx}$ & リ & 二 & 相 & 剔 & 广 & y) & 最 & 殖 & 論 & X & 秙 & 及 \\
\hline 時 & $\stackrel{s}{7}$ & & 內 & 互 & 出 & 程 & 0 & 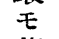 & 腺 & & 天 & 稍 & र \\
\hline 古 & $\Xi$. & 殊 & 分 & 的 & & 度 & 余 & 著 & & & ナ & 增 & 冈 \\
\hline 置 & 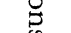 & $=$ & 浘 & 關 & 生 & 7 & ' & 明 & 甲 & & U & 加 & 分 \\
\hline J & $\widehat{D}$ & 声 & 墕 & 俕 & 外 & 瓷 & 資 & 二 & 將 & & モ & 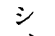 & 泌 \\
\hline $\bar{E}$ & $\vec{\sigma}$ & 紊 & 凋 & $=$ & 慆 & 跣 & 频 & 特 & 腺 & & ' & & 祖 \\
\hline ) & $F$ & 柏 & ( & f & 軖 & シ & $=$ & 然 & 及 & & 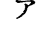 & 却 & 器 \\
\hline$=$ & $\breve{\Xi}$ & ש & $\begin{array}{l}\text { 沿能 } \\
\end{array}$ & + & 鼬 & 菨 & r & 絽 & E & & u & " & 剔 \\
\hline $\boldsymbol{P}$ & 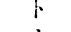 & $\gamma$ & 䏩 & 不 & 出 & 㬛 & $\frac{\pi}{\tau}$ & ת & $\begin{array}{l}\text { 副 } \\
\prod^{2}\end{array}$ & & 田 & 7 & 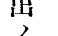 \\
\hline . & 1 & v) & 䈃 & 明 & & t & 前 & 出 & 型 & & 悹 & P & 影 \\
\hline ザ & t & $\bar{T}$ & $=$ & $=$ & 甲 & u & 述 & 現 & $\equiv$ & & シ & 弯 & 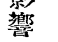 \\
\hline נ & 甾 & 斯 & $\exists$ & 屬 & 狀 & モ & 諸 & त & 者 & & 厶 & 單單 & 战 \\
\hline ⿵. & 狀 & ク & リ) & ス & 腺 & ) & 内 & U & , & & & 蟼 & $\neq$ \\
\hline 0 & 腺 & 加 & gith & $i$ & 埋品 & $\exists$ & 分 & 7 & 間 & & & 剔 & $\vec{\tau}$ \\
\hline 筜 & 剔 & $\begin{array}{l}\text { M } \\
\neq \\
\neq\end{array}$ & 呅 & 巩 & 剔 & 列 & 留 & 酧 & 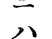 & & & 出 & \\
\hline & 出 & 組 & & $\bar{J}$ & 出 & 擧 & נ, & 得 & 互 & & & 沂 & 猫 \\
\hline & 际 & 織 & 般 & n & & 入 & 剔 & べ & $=$ & & & $\neq$ & \\
\hline & 見 & 旳 & 湙 & 基 & 副 & $v$ & 出 & $\eta$ & 密 & & & モ & \\
\hline 昭 & $\pi$ & 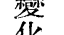 & 棵 & 起 & 㛑 & 公 & 後 & 由 & ナ & & & ' & - \\
\hline 盉 & ¿ & 化 & 代 & 源 & 慗 & 生 & $\stackrel{1}{+\Delta}$ & 奛 & ル & & & $>$ & 五 \\
\hline 年 & 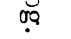 & 무 & 裂 & $\begin{array}{l}\text { 召 } \\
\text { 严 }\end{array}$ & 䛬 & 外皇 & 於 & 妝 & 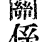 & & & $\left.{ }^{3}\right)$ & \\
\hline 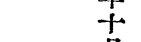 & & 吾 & 䒫 & 要 & 出 & 椘 & $\begin{array}{l}T \\
u\end{array}$ & 暘 & 棸 & & & ב & \\
\hline & $\sqrt{5}$ & タ & $=$ & 緝 & 录 & 岱 & 腦 & 出 & u & & & $\vec{v}$ & \\
\hline 十 & 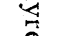 & ル & 異 & 胞 & 順 & 狀 & 下 & $=$ & べ & & & 白 & \\
\hline 日 & 8 & モ & 變 & $=$ & ナ & 腺 & 垂 & 2 & $\neq$ & & & 鼠 & \\
\hline 脫 & & ) & 7 & $>$ & & 重 & 體 & $=$ & モ & & & & \\
\hline 樆 & $\frac{d}{d x}$ & ナ & 起 & U & & 複 & I & 次 & 白 & & & 列 & \\
\hline & Of & ル & シ & モ & ב & 剔 & 重。 & ギ & 鼠 & & & & \\
\hline & & ベ & & 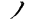 & & & 量 & & $=$ & & & & \\
\hline & & n & 直 & ナ & ラ & & 燴 & 副 & 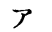 & & & & \\
\hline
\end{tabular}




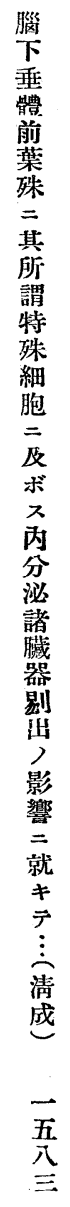

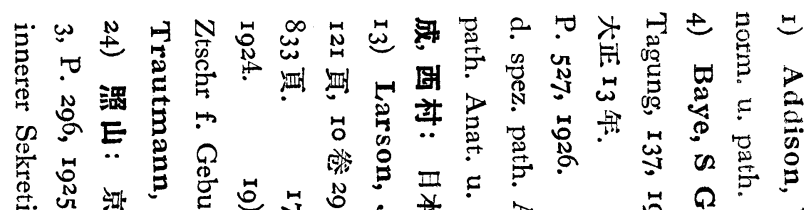

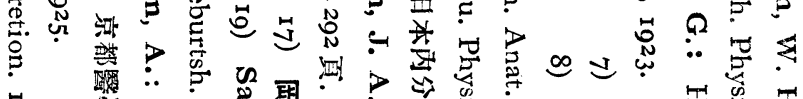

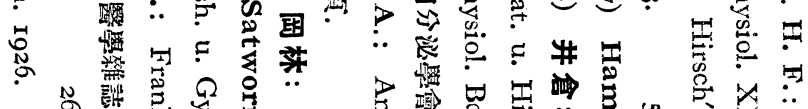

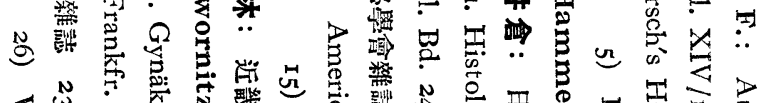
전

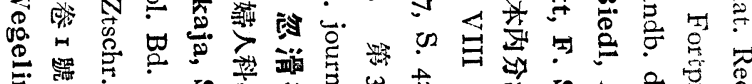

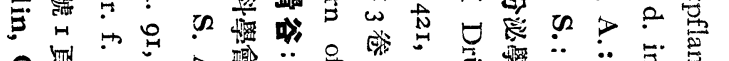

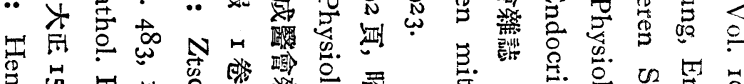

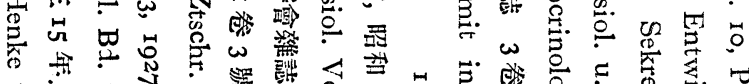
ᄃ.

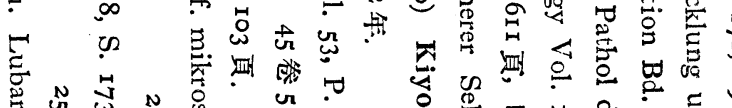

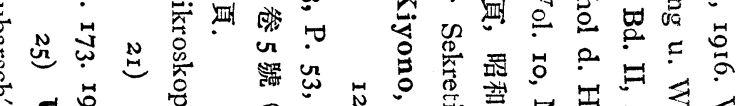

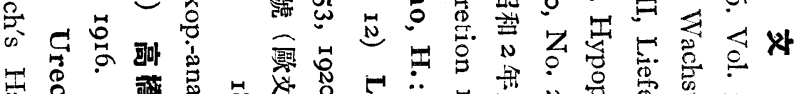

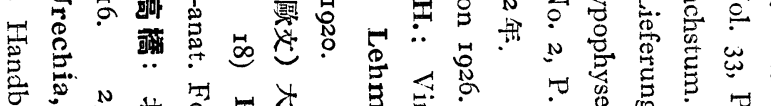

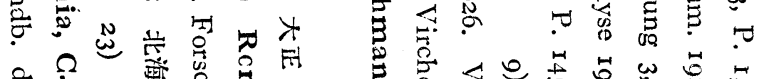

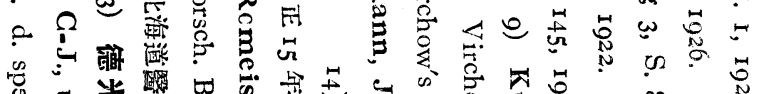

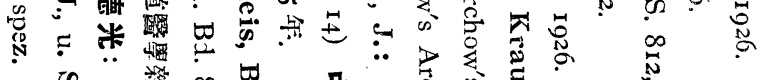

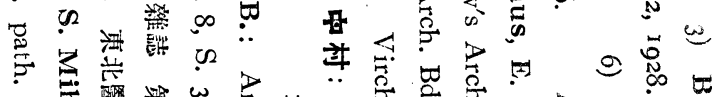

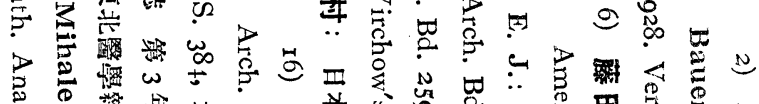

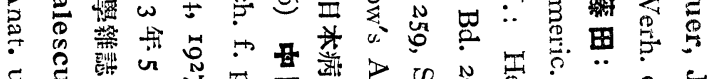

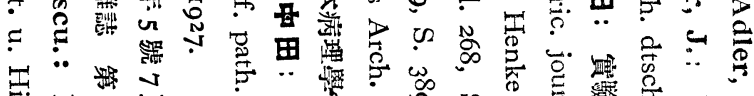

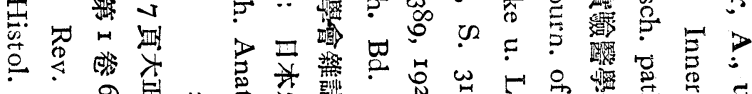

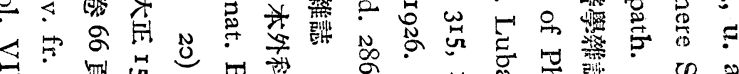

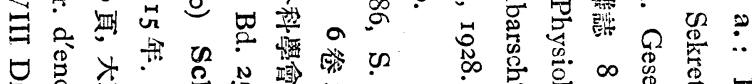

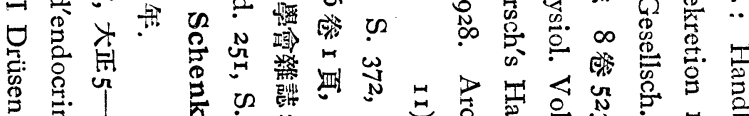

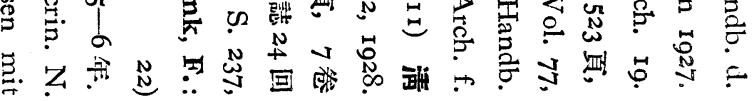




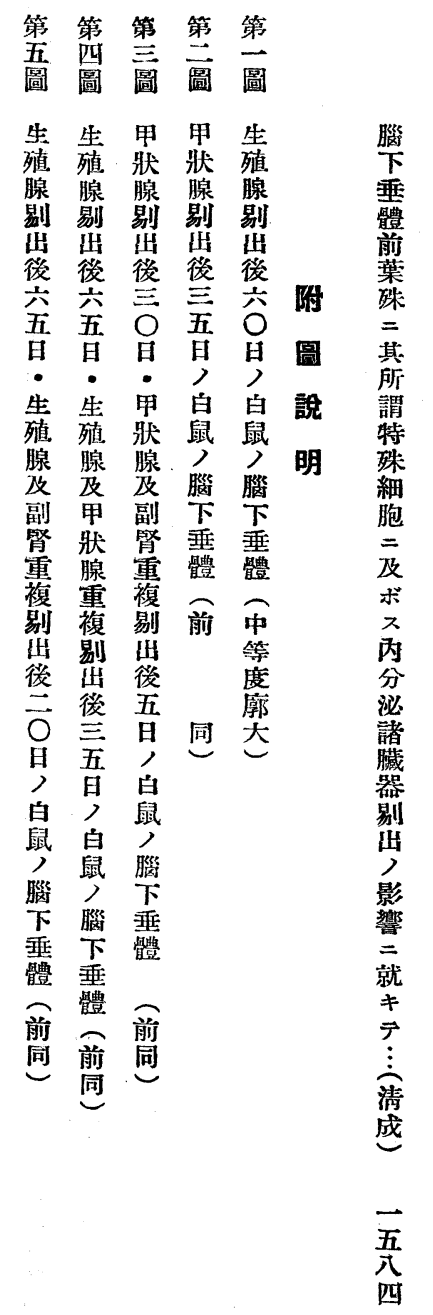



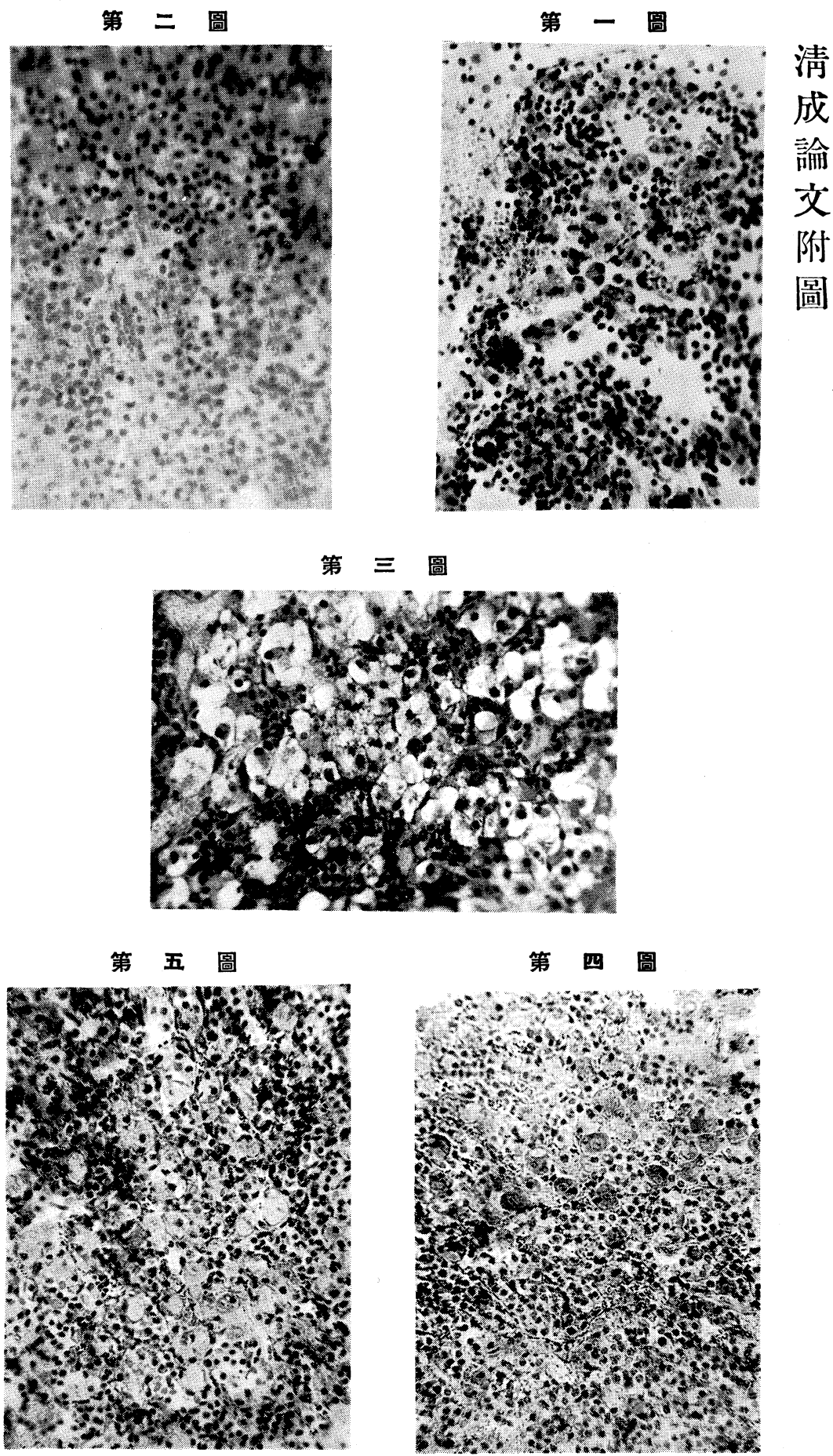


\section{FOLIA ENDOCRINOLOGICA JAPONICA}

\begin{tabular}{llc}
\hline Band IV & DEZEMBER & Heft 9 \\
\hline
\end{tabular}
UEBER DEN EINFLUSS DER ENTFERNUNG DER VERSCHIEDENEN ENDOKRINEN DRÜSEN AUF
DIE HISTOLOGISCHEN VER ÄNDERUNGEN
DES HYPOPHYSENVORJERLAPPENS, BESONDERS AUF DIE IN DEMSELBEN
BEOBACHTETEN SOGENANNTEN
" SPEZIFISCHEN ZELLEN"
Von

Dr. Y. Kiyonari.

(Aus der I. med. Klinik der kaiser!. Univers, zu Kyoto.

Direktor: Prof. Dr. K. Tsuji.)

Um die sogenannten ,, spezifischen Zellen " im "Vorderlappen der Hypophyse kennen zu lernen, führte der Verfasser an jungen weissen Ratten einfache oder kombinierte Entfernung der Keimdrüsen, Schilddrüsen u. Nebenieren aus.

Die Resultate lassen sich kurz wie folgt zusammenfassen:

Im epithelialen Hauptteil der Hypophyse, der für Verfassers Untersuchung hauptsächlich in Betracht kam, fand dieser die grossen, blasigen Zellen mit blaurötlich granuliertem Protoplasma u. blass gefärbtem Kern nicht nur bei den keimdrüsenlosen Tieren sondern auch bei den schilddrüsen- oder nebennierenlosen, wenn auch die Zellform u. das Stadium ihres Auftretens mehr oder weniger 
verschieden waren.

Bei Rerücksichtigung des Auftretens der oben beschriebenen sogenannten ", spezifischen Zellen" und der Zunahme des Hypophysengewichtes lassen sich die Veränderungen der Hypophyse in der nachstehenden Reihenfolge verzeichnen: Kombinierte Entfernung der Keim- u. Schilddrüsen, kombinierte Entfernung der Keimdrüsen u. Nebennieren, kombinierte Entfernung der Schilddrüsen u. Nebennieren, einfache Entfernung der Keimdrüsen, einfache Entfernung der Schilddrüsen u. einfache Entfernung der Nebennieren. Die sogenannten „spezifischen Zellen” gehen vermutlich aus den chromophoben Hauptzellen hervor. Die Bedeutung dieser Veränderung ist aber leider noch unklar. Jedenfalls ist es gut denkbar, dass infolge des Ausfalls der oben geschilderten innersekretorischen Diüsen im ganzen Organismus allgemeine Stoffwechselstörungen eintreten u. diese direkt oder indirekt auf die Funktion der Hypophyse, besonders auf die der chromophoben Zellen einwirken u. schliesslich diese in die sogenannten ,spezifischen Zellen" übergehen. Endlich glaubt der Verfasser, dass die bei keimdrüsenlosen Tieren beobachteten sogenannten „Kastrationszellen" oder die bei schilddrüsenlosen beobachteten sogenannten "Thyreoidektomiezellen" etc. für die Kastration oder die Schilddrüsenexstirpation allein nicht spezifisch sind. (Autoreferat.)

\title{
UEBER DEN EINFLUSS VERSCHIEDENER INNERER SEKRETE AUF DEN FETT- UND \\ LIPOIDGEHALT DER NEBENNIERE, DES OVARIUMS UND DES BLUTES.
}

\section{Von}

\author{
Dr. T. Kohno.
}

(Aus der I. med` Klinik der kaiserl. Universitaet zu Kyoto Direktor : Prof. Dr. K. Tsuji.) 